\title{
Correlation of ADC values measured using 3T diffusion- weighted MRI and SUVs from fluorodeoxyglucose PET/CT in head and neck squamous cell carcinomas
}

\author{
(1) Edis Çolak', (1) Selen Bayraktaroğlu², (1) Özlem Akagündüz ${ }^{3}$, (1) Recep Savaş², (1) Mustafa Esassolak ${ }^{3}$ \\ 1 University of Health Sciences Turkey, Dr. Behçet Uz Child Disease and Pediatric Surgery Training and Research Hospital, \\ Clinic of Radiology, Izmir, Turkey \\ ${ }^{2}$ Ege University Faculty of Medicine, Department of Radiology, Izmir, Turkey \\ ${ }^{3}$ Ege University Faculty of Medicine, Department of Radiation Oncolgy, Izmir, Turkey
}

Date submitted:

05.06.2019

Date accepted:

13.11.2019

Online publication date:

15.06.2020

\section{Corresponding Author:}

Edis Çolak MD, University of Health

Sciences Turkey, Dr. Behçet Uz

Child Disease and Pediatric Surgery

Training and Research Hospital, Clinic of Radiology, Izmir, Turkey

edisramo@yahoo.com

ORCID:

orcid.org/0000-0001-5191-0491

Keywords: Apparent diffusion coefficient, head and neck squamous cell carcinoma, diffusion-weighted magnetic resonance imaging, positron emission tomography, standardized uptake value

\begin{abstract}
Aims: The aim of our study was to assess the correlations between apparent diffusion coefficient (ADC) values and standardized uptake values (SUVs) and their correlations with tumor size, tumor stage and histological grade in patients with head and neck squamous cell carcinomas (HNSSCs).

Methods: This retrospective study included 36 patients with histologically confirmed HNSSCs visible on diffusion weighted imaging (DWI) and fluorodeoxyglucose (FDG) positron emission tomography $(\mathrm{PET} / \mathrm{CT})$. Correlations of minimum $\mathrm{ADC}\left(\mathrm{ADC} \mathrm{m}_{\mathrm{min}}\right)$, mean $\mathrm{ADC}(\mathrm{ADC}$ mean $)$, and minimum-mean $A D C$ ratio $\left(A D C_{\text {min/mean }}\right)$ with maximum SUV ( $\left.S U V_{\text {max }}\right)$ and lean body mass $\mathrm{SUV}_{\mathrm{lbm}}\left(\mathrm{SUV}_{\mathrm{lbm}}\right)$ were analyzed using the Spearman's correlation test. The Kruskal-Wallis one-way ANOVA test and Mann-Whitney $U$ test were used to assess the correlations of ADC values and SUVs with tumor size, tumor stage and histological grade. Two experienced readers measured the ADC and SUVs independently, and intraclass correlation coefficient (ICC) was used to analyze the inter-observer agreement.
\end{abstract}

Results: The mean $A D C_{\text {min }}, A D C_{\text {mean }}$, and $A D C_{\text {min }} /$ mean for HNSSCs were $0.68 \pm 0.17 \times 10^{-3}$ $\mathrm{mm}^{2} / \mathrm{s}, 0.82 \pm 0.17 \times 10^{-3} \mathrm{~mm}^{2} / \mathrm{s}$, and $0.83 \pm 0.10$, respectively. The mean SUV $\max$ and SUV $\mathrm{lbm}_{\mathrm{bm}}$ were $14.65 \pm 5.5$ and $10.96 \pm 5.1$, respectively. The correlations between ADC values and SUVs did not reach statistical significance. There were no significant correlations of ADC values and SUVs with tumor size, tumor stage or histological grade. There was a tendency of SUVs to increase and ADC values to decrease with tumor dedifferentiation; however, the changes were not significant. Inter-observer agreement for tumor ADC values and SUVs was almost perfect $(\mathrm{ICC}>0.81)$.

Conclusions: Pretreatment ADC values and SUVs in HNSSCs are reproducible and independent biomarkers.

\section{Introduction}

Head and neck carcinomas account for over $6 \%$ of all malignant tumors in adults worldwide. Over $90 \%$ of malignant head and neck tumors are squamous cell carcinomas. According to the guidelines of American Joint Committee on Cancer, the tumor node metastasis staging of head and neck cancer requires histopathological diagnosis and additional imaging (1). Fluorodeoxyglucose (FDG) positron emission tomography/ computed tomography (PET/CT) and diffusion weighted magnetic resonance imaging (DW MRI) are increasingly recognized as important for assessing tumor malignancy in oncology.

Although DW imaging (DWI) and FDG PET/CT are based on different physical principles, both techniques are highly successful in oncology clinical practice and widely applied in tumor diagnosis (2). DWI is based on the assessment of 
Brownian motion at the molecular level. The more restricted the movement of extracellular water molecules, the brighter it will be on DWI sequences. Malignant tumors exhibit hypercellularity, increased nucleus-to-cytoplasm ratios, and less extracellular space resulting in decreased apparent diffusion coefficient (ADC) values on ADC map. Based on previous studies, it appears that most malignant tissues have lower ADC values compared to normal tissue because of their higher cellular density (3). On the other hand, FDG PET/CT is a simple and reliable method of evaluating the glucose uptake capacity of tumors in vivo. Hypercellular tumor cells show increased intracellular accumulation of the glucose analog FDG, which is expressed by an increased standardized uptake value (SUV) (4). Since both SUV and ADC provide information on tumor cellularity, some degree of correlation between these two quantitative imaging parameters could be expected $(4,5)$. An inverse association has been demonstrated between SUV and ADC values in studies of gastrointestinal stromal tumor, cervix cancer, rectal cancer, breast cancer, lung cancer and lymphoma (5-8). Previous reports found diverging results with either no correlation or significant correlation between SUV and ADC values in head and neck squamous cell carcinomas (HNSCCs).

The present study aimed to assess the reproducibility and correlations between ADC values and SUVs and their correlations with tumor size, tumor stage and histological grade in the same patients with biopsy-proven primary HNSSCs. Present review focuses on the promises of noninvasive imaging modalities in the initial diagnostic and prognostic assessment of patients with HNSSCs.

\section{Methods}

\section{Ethical approval}

Approval for the study was granted by the Ethics Committee of Ege University Faculty of Medicine (approval date: February 12, 2013, approval number: 13-1/50). It was conducted in accordance with the Declaration of Helsinki.

\section{Patients}

This study retrospectively analyzed 36 patients with histologically proven HNSSCs, who underwent head and neck MRI, DWI and whole-body FDG PET/CT examinations between October 2011 and September 2013. The mean time between FDG PET/CT and MRI was 7 days. Biopsy was performed 10-20 days after FDG PET/CT and MRI examinations (average time 15 days). The inclusion criteria for this study were as follows: patients at least 18 years of age who were previously untreated for head and neck carcinomas, no palpable neck lymph nodes, and available pretreatment FDG PET/CT, head and neck MRI and DWI. The exclusion criteria included the presence of palpable metastatic neck lymph nodes, a history of previous treatment for HNSSCs, distant metastasis at initial presentation, poor image quality. A total of 16 patients were excluded owing to susceptibility to artifacts that jeopardized image quality. Eight patients, who received radiotherapy (RT), were also excluded from the study. Therefore, 36 patients with HNSSCs were finally included in this study.

\section{MRI and DWI}

A 3-T whole-body system (Verio, Siemens Medical Systems, Germany) with a neck array coil was used to perform MRI examinations. The maximum gradient capability was 40 $\mathrm{mT} / \mathrm{m}$, and the maximum slew rate was $200 \mathrm{mT} / \mathrm{m}$. The MRI protocol included the following imaging sequences: axial T1weighted imaging [repetition time (TR)/echo time (TE), 623/9; NEX, 2; matrix, $320 \times 224$; field of view (FOV), $27 \mathrm{~cm}$; slice thickness, $4 \mathrm{~mm}$; intersection gap, $1.5 \mathrm{~mm}$; 20 sections], sagittal T1-weighted imaging (TR/TE, 730/9.6; NEX, 2; matrix, $384 \times$ 269; FOV, $27 \mathrm{~cm}$; slice thickness, $5 \mathrm{~mm}$; intersection gap, $1.5 \mathrm{~mm}$; 20 sections), coronal T1-weighted imaging (TR/TE, 803/9.6; NEX, 2; matrix, $384 \times 288$; FOV, 27 cm; intersection gap, $1.5 \mathrm{~mm}$; slice thickness, $5 \mathrm{~mm}$; 20 sections), axial Turbo Inversion Recovery Magnitude (TIRM) [TR/TE/inversion time (TI), 3480/56/220; NEX, 2; matrix, $320 \times 224$; FOV, 27 cm; slice thickness, $4 \mathrm{~mm}$; intersection gap, $1 \mathrm{~mm}$; 20 sections], sagittal TIRM (TR/TE/TI, 4110/55/220; NEX, 2; matrix, $320 \times$ 240; FOV, $27 \mathrm{~cm}$; slice thickness, $5 \mathrm{~mm}$; intersection gap, 1 mm; 20 sections), and coronal TIRM (TR/TE/TI, 4462/55/220; NEX, 2; matrix, $320 \times 240$; FOV, $27 \mathrm{~cm}$; intersection gap, $1 \mathrm{~mm}$; slice thickness, $5 \mathrm{~mm} ; 20$ sections). Axial DWI was performed using a fat suppression single-shot echo-planar technique (TR/ TE/TI, 14200/77/220; NEX, 2; matrix, $100 \times 100$; FOV, 27 cm; slice thickness, $4 \mathrm{~mm}$; no intersection gap; 52 sections). ADC values were determined using the following two $b$ factors: $b 0$ and $b 800 \mathrm{~s} / \mathrm{mm}^{2}$. ADC maps were automatically formed on a pixel-by-pixel basis by an MRI software system. To locate the solid tumor portion accurately, $0.1 \mathrm{mmol} / \mathrm{kg}$ gadolinium-DTPAenhanced T1-weighted spin-echo imaging with fat suppression was performed after DWI. The ADC values were measured on $A D C$ maps by drawing a region of interest (ROI) around the largest solid portion of the tumor avoiding any cystic or necrotic areas identified on the TIRM and T1-weighted post-contrast MR images. ROI examples are shown in Figure 1. The size of the ROI was $16-56 \mathrm{~mm}^{2}$. The minimum ADC $\left(\mathrm{ADC}_{\text {min }}\right.$, the lowest $A D C$ value within the ROI, which is based on a single pixel), mean $A D C\left(A D C_{\text {mean }}\right.$, the mean $A D C$ value of all the pixels within the $R O I)$, and minimum-mean $A D C$ ratio $\left(A D C_{\text {min/mean }}\right)$ were calculated within the same ROI.

\section{FDG PET/CT}

The PET-CT scanner used in this study was a Biograph 16-slice PET/CT scanner (Siemens Healthcare, Germany). The patients were instructed not to eat food for six hours before the PET/CT imaging. In patients whose preparation 
was adequate, the blood glucose level was checked and, at the time of FDG injection, serum glucose levels were $150 \mathrm{mg} / \mathrm{dL}$ or less. In all patients, fluorine-18 FDG (18F-FDG) of $3.7 \mathrm{MBq} /$ $\mathrm{kg}$ body weight was intravenously injected. After the injection, the patients were requested to rest for one hour. At the end of the resting period, the patients were asked to empty their bladder. All the patients were scanned from the vertex to the proximal thigh. PET emission scans were performed with 1.8 min per bed position for a total of 7 to 10 beds. PET images were scatter-corrected and reconstructed using an orderedsubset expectation maximization iterative reconstruction algorithm. The reconstruction parameters were as follows: three iterations and twenty one subsets. The CT parameters were as follows: tube voltage, $130 \mathrm{kVp}$; tube current, $120 \mathrm{~mA}$; collimation, $16 \times 1.5$; FOV, 500 mm; matrix, $512 \times 512$; gantry rotation, $0.6 \mathrm{~s}$; gantry feed per rotation, $30 \mathrm{~mm}$; slice width, 5 $\mathrm{mm}$. The PET/CT images were shown on a monitor. Tumor was distinguished on PET/CT images, and a 3D ROI, which included the whole lesion in the sagittal, coronal and axial planes, was placed in the PET dataset. ROI examples are shown in Figure 1. The SUV by body weight was calculated using this formula: SUV = [radioactivity concentration in tissue (Bq) / tissue weight $(\mathrm{g})$ ] / [total injected dose $(\mathrm{Bq}) /$ patient's body weight $(\mathrm{g})$ ]. The maximum SUV $\left(\mathrm{SUV}_{\max }\right)$ is merely a
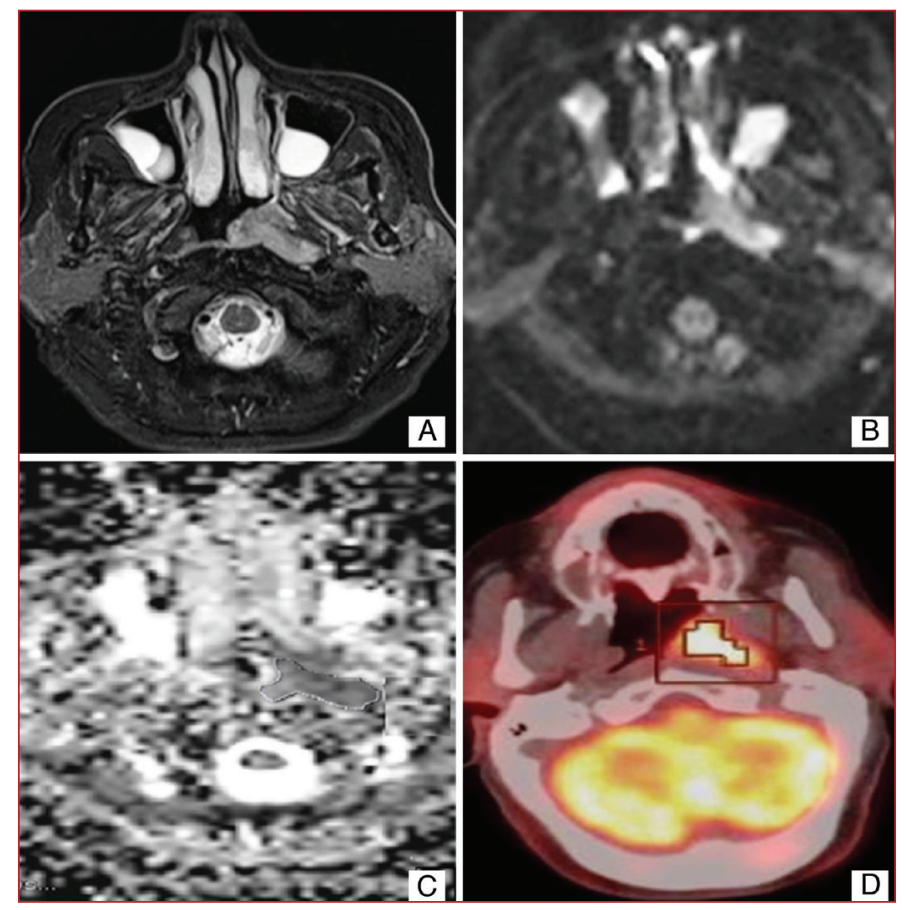

Figure 1. A 58-year-old woman with left well-differentiated nasopharyngeal cancer. The tumor is clearly delineated on axial Turbo Inversion Recovery Magnitude imaging (A). The tumor shows high signal intensity on diffusion-weighted imaging (b: 800) (B) and low signal intensity in an apparent diffusion coefficient map (C). Fluorodeoxyglucose positron emission tomography/computed tomography shows strong uptake in the tumor (D). Regions of interest are shown in C and D single-voxel value representing the most intense FDG uptake of the structure delineated by the ROI. The SUV normalized to lean body mass $\left(S U V_{\mathrm{Ibm}}\right)$ was defined as follows: SUV = (activity in the 9 maximal pixels in $\mathrm{mCi} / \mathrm{mL}$ ) / (total injected dose / lean body mass). The corresponding volume measured automatically by the software was marked as metabolic tumor volume (MTV). DW MRI and PET/CT measurements were performed by two board-certified radiologists. The radiologists were informed on the clinical diagnosis of HNSSCs but were blinded to the pathologic findings and the patients' previous history. The readers measured ADC values and SUVs, independently, using the predefined ROI size. The measured values were recorded.

\section{Statistical Analysis}

The relationships between $A D C$ values $\left(A D C_{\text {min }}, A D C_{\text {mean }}\right.$, and $A D C_{\text {min/mean }}$ ) and SUVs (SUV max and $\left.S U V_{l b m}\right)$ were determined by the Spearman's rank test. The Kruskal-Wallis One-Way analysis of variance (ANOVA) test and Mann-Whitney $U$ test were used to examine the associations of SUVs and ADC values with tumor size, MTV, tumor stage, and tumor histological grade (9). According to Donner and Koval (10), Landis and Koch (11), intraclass correlation coefficients (ICCs) values for inter-observer agreement with 95\% confidence intervals were represented as follows: $\leq 0$, no agreement; 0.01-0.20, none to slight agreement; 0.21-0.40, fair; 0.41-0.60, moderate; 0.610.80 , substantial; and 0.81-1.00, almost perfect agreement. Statistical data were analyzed using the SPSS software version 15.0 (SPSS Inc., Chicago, IL, USA). Statistical significance was set at $p$-value of $\leq 0.05$.

\section{Results}

This retrospective study was conducted on 36 patients (20 men and 16 women) with HNSSCs.

The mean age was $56.4 \pm 9.8$ years (range, $18-80$ years). The primary tumor sites were as follows: nasopharynx $(n=14)$, larynx $(n=8)$, hypopharynx $(n=4)$, oral cavity $(n=4)$, oropharynx $(n=3)$, paranasal sinuses $(n=2)$, and external auditory canal $(n=1)$. The mean tumor size according to the longest tumor diameter measured in the axial plane was $5.26 \pm 2.04 \mathrm{~cm}$ (range, $1-10 \mathrm{~cm}$ ). The mean tumor volume was $22.3 \pm 26.9 \mathrm{~cm}^{3}$ (range, $\left.3.2-104 \mathrm{~cm}^{3}\right)$. Among the 36 tumors, 10 (27.8\%) were poorly differentiated, 20 (55.5\%) were moderately differentiated, and 6 $(16.7 \%)$ were well differentiated. The diagnosed head and neck carcinomas were staged as T1 $(n=6,16.7 \%)$, T2 $(n=16,44.4 \%)$, T3 $(n=11,30.6 \%)$, and T4 tumors $(n=3,8.3 \%)$ with no additional nodal or distant metastases.

\section{ADC values and SUVs in HNSSCs}

Table 1 summarizes the ADC values and SUVs for all the HNSSCs. The mean $A D C_{\text {min }}, A D C_{\text {mean }}$, and $A D C_{\text {min/mean }}$ for the HNSSCs were $0.68 \pm 0.17 \times 10^{-3} \mathrm{~mm}^{2} / \mathrm{s}, 0.82 \pm 0.17 \times 10^{-3}$ 
Table 1. Apparent diffusion coefficient values and standardized uptake values for head and neck squamous cell carcinomas

\begin{tabular}{|c|c|c|c|c|}
\hline Biomarker & $\begin{array}{l}\text { HNSSC }(n=36) \\
\text { Mean } \pm S D\end{array}$ & Median & Minimum & Maximum \\
\hline $\mathrm{ADC}_{\min }\left(10^{-3} \mathrm{~mm}^{2} / \mathrm{s}\right)$ & $0.68 \pm 0.17$ & 0.69 & 0.33 & 0.99 \\
\hline $\mathrm{ADC}_{\min / \text { mean }}$ & $0.83 \pm 0.10$ & 0.84 & 0.53 & 0.97 \\
\hline SUV $_{\max }$ & $14.65 \pm 5.50$ & 13.10 & 7.60 & 29.10 \\
\hline
\end{tabular}

Table 2. Correlations between apparent diffusion coefficient values and standardized uptake values in head and neck squamous cell carcinomas

\begin{tabular}{|c|c|c|c|}
\hline & $A D C_{\min }$ & $A D C_{\text {mean }}$ & $A D C_{\text {min/mean }}$ \\
\hline \multirow{2}{*}{$\mathrm{SUV}_{\text {max }}$} & $r=-0.050$ & $r=-0.084$ & $r=-0.160$ \\
\hline & $p=0.777$ & $p=0.630$ & $p=0.359$ \\
\hline \multirow{2}{*}{ SUV $_{\mathrm{lbm}}$} & $r=-0.057$ & $r=-0.090$ & $r=-0.141$ \\
\hline & $p=0.746$ & $p=0.606$ & $p=0.419$ \\
\hline
\end{tabular}

$\mathrm{mm}^{2} / \mathrm{s}$, and $0.83 \pm 0.10 \mathrm{~mm}^{2} / \mathrm{s}$, respectively. The mean $\mathrm{SUV}_{\max }$, SUV $_{\mathrm{Ibm}}$, and MTV were $14.65 \pm 5.5,10.96 \pm 5.1$, and $22.3 \pm 26.9$ $\mathrm{cm}^{3}$, respectively.

\section{Correlations of ADC values and SUVs in HNSSCs}

There were no significant correlations between the ADC values $\left(A D C_{\text {min }}, A D C_{\text {mean }}\right.$, and $\left.A D C_{\text {min/mean }}\right)$ and the SUV values $\left(\mathrm{SUV}_{\max }\right.$ and $\left.\mathrm{SUV}_{\mathrm{lbm}}\right)($ Table 2$)$.

Correlations of ADC values and SUVs with tumor size and MTV

ADC values and SUVs were not significantly associated with tumor size and MTV.

Correlations of ADC values and SUVs with tumor histological grade

For well-differentiated tumors, the mean $A D C_{\text {min }}, A D C_{\text {mean }}$ $\mathrm{ADC}_{\text {min/mean }}, \mathrm{SUV}_{\text {max }}$, and $\mathrm{SUV}_{\mathrm{lbm}}$ were $0.72 \pm 0.23 \times 10^{-3}$ $\mathrm{mm}^{2} / \mathrm{s}, 0.89 \pm 0.17 \times 10^{-3} \mathrm{~mm}^{2} / \mathrm{s}, 0.79 \pm 0.15,13.30 \pm 4.7$, and $9.5 \pm 3.6$, respectively. For moderately differentiated tumors, the mean $A D C_{\text {min }}, A D C_{\text {mean }}, A D C_{\text {min/mean }}, S U V_{\text {max }}$, and SUV $_{\mathrm{lbm}}$ were $0.72 \pm 0.19 \times 10^{-3} \mathrm{~mm}^{2} / \mathrm{s}, 0.84 \pm 0.21 \times 10^{-3}$ $\mathrm{mm}^{2} / \mathrm{s}, 0.86 \pm 0.08,15.30 \pm 5.6$, and $11.4 \pm 5.1$, respectively. For poorly differentiated tumors, the mean $A D C_{\text {min }}, A D C_{\text {mean }}$, $\mathrm{ADC}_{\text {min/mean }}$, SUV $\max$, and $S U V_{\mathrm{lbm}}$ were $0.64 \pm 0.14 \times 10^{-3}$ $\mathrm{mm}^{2} / \mathrm{s}, 0.78 \pm 0.15 \times 10^{-3} \mathrm{~mm}^{2} / \mathrm{s}, 0.82 \pm 0.10,15.5 \pm 7.2$, and $12.8 \pm 7.4$, respectively (Table 3 ). There was a tendency for the
SUVs to increase and the ADC values to decrease with tumor dedifferentiation; however, these changes were not significant.

\section{Correlations of ADC values and SUVs with tumor stage}

The mean $\mathrm{ADC}_{\text {min }}, \mathrm{ADC}_{\text {mean }}, \mathrm{ADC}_{\text {min/mean }}, \mathrm{SUV}_{\text {max }}$, and SUV lbm $_{\text {were }} 0.69 \pm 0.19 \times 10^{-3} \mathrm{~mm}^{2} / \mathrm{s}, 0.82 \pm 0.16 \times 10^{-3}$ $\mathrm{mm}^{2} / \mathrm{s}, 0.85 \pm 0.08,12.10 \pm 4.1$, and $9.37 \pm 3.3$ for $\mathrm{T} 1-2$ stage, and $0.67 \pm 0.16 \times 10^{-3} \mathrm{~mm}^{2} / \mathrm{s}, 0.80 \pm 0.20 \times 10^{-3} \mathrm{~mm}^{2} / \mathrm{s}, 0.81 \pm 0.11$, 16.15 \pm 5.6 , and $11.89 \pm 5.5$ for T3-4 stage, respectively (Table 3 ). Although statistically insignificant, a trend towards higher SUVs and lower ADC values was observed in T3-4 stage (Table 3).

\section{Inter-observer agreement}

Inter-observer agreement for tumor $A D C_{\min }, A D C_{\text {mean }}$, SUV $_{\text {max }}$ and SUV $_{\mid \mathrm{bm}}$ values was almost perfect $(I C C>0.81)$ (Table 4).

\section{Discussion}

Our study found no significant associations between the ADC values and the SUVs. Additionally, correlations between the ADC values and the SUVs with tumor size, tumor stage or tumor histological grade did not reach statistical significance.

\section{ADC values for HNSSCs}

In the present study, the $A D C$ values $\left(A D C_{\text {min }}, A D C_{\text {mean }}\right.$, and $A D C_{\text {min/mean }}$ ) were calculated from $b$ values of 0 and $800 \mathrm{~s} /$ $\mathrm{mm}^{2}$. High b values eliminate the perfusion effect (12). The ADC values in our study were obtained at $3 \mathrm{~T}$. With the exception of one study (13), previous studies found that the ADC values were independent of the magnetic field strength (14-16). ADC measurements at 1.5, 3 and $7 \mathrm{~T}$ found no statistically significant difference for ADC values either in the breast, head and neck or in the abdomen, provided that the parameters of the DWI used were identical (14-16). The ADC values for the HNSSCs in the present study are similar to those reported in previous studies (17-29). In the present study, the mean $A D C_{\text {min }}, A D C_{\text {mean }}$, and $A D C_{\text {min }} /$ mean for the HNSSCs were $0.68 \pm 0.17 \times 10^{-3} \mathrm{~mm}^{2} / \mathrm{s}$ (range, $0.33-0.99 \times 10^{-3} \mathrm{~mm}^{2} / \mathrm{s}$ ), $0.82 \pm 0.17 \times 10^{-3} \mathrm{~mm}^{2} / \mathrm{s}$ (range, $0.44-1.25 \times 10^{-3} \mathrm{~mm}^{2} / \mathrm{s}$ ), and $0.83 \pm 0.10 \mathrm{~mm}^{2} / \mathrm{s}$ (range, 


\begin{tabular}{|c|c|c|c|c|c|c|c|c|c|}
\hline Biomarker & $\begin{array}{l}\text { Histologic } \\
\text { grade }\end{array}$ & Number & Mean $\pm S D$ & $\mathbf{p}^{*}$ & Biomarker & $\begin{array}{l}\text { Tumor } \\
\text { stage }\end{array}$ & Number & Mean $\pm S D$ & $\mathbf{p}^{*}$ \\
\hline \multirow[t]{3}{*}{$\begin{array}{l}A D C_{\min } \\
\left(10^{-3} \mathrm{~mm}^{2} / \mathrm{s}\right)\end{array}$} & WDC & 10 & $0.72 \pm 0.23$ & 0.526 & $\begin{array}{l}A D C_{\min } \\
\left(10^{-3} \mathrm{~mm}^{2} / \mathrm{s}\right)\end{array}$ & T1-2 & 22 & $0.69 \pm 0.19$ & 0.745 \\
\hline & MDC & 20 & $0.72 \pm 0.19$ & & & T3-4 & 14 & $0.67 \pm 0.16$ & \\
\hline & PDC & 6 & $0.64 \pm 0.14$ & & & & & & \\
\hline \multirow[t]{3}{*}{$\begin{array}{l}A D C_{\text {mean }} \\
\left(10^{-3} \mathrm{~mm}^{2} / \mathrm{s}\right)\end{array}$} & WDC & 10 & $0.89 \pm 0.17$ & 0.274 & $\begin{array}{l}A D C_{\text {mean }} \\
\left(10^{-3} \mathrm{~mm}^{2} / \mathrm{s}\right)\end{array}$ & T1-2 & 22 & $0.82 \pm 0.16$ & 0.820 \\
\hline & MDC & 20 & $0.84 \pm 0.21$ & & & T3-4 & 14 & $0.80 \pm 0.20$ & \\
\hline & PDC & 6 & $0.78 \pm 0.15$ & & & & & & \\
\hline \multirow[t]{3}{*}{$A D C_{\min / \text { mean }}$} & WDC & 10 & $0.80 \pm 0.15$ & 0.540 & $A D C_{\min / \text { mean }}$ & T1-2 & 22 & $0.84 \pm 0.08$ & 0.757 \\
\hline & MDC & 20 & $0.86 \pm 0.08$ & & & T3-4 & 14 & $0.83 \pm 0.11$ & \\
\hline & PDC & 6 & $0.82 \pm 0.10$ & & & & & & \\
\hline \multirow[t]{3}{*}{ SUV $_{\text {max }}$} & WDC & 10 & $13.30 \pm 4.7$ & 0.983 & SUV $_{\text {max }}$ & T1-2 & 22 & $12.10 \pm 4.1$ & 0.622 \\
\hline & MDC & 20 & $15.30 \pm 5.6$ & & & T3-4 & 14 & $16.15 \pm 5.6$ & \\
\hline & PDC & 6 & $15.5 \pm 7.2$ & & & & & & \\
\hline \multirow[t]{3}{*}{ SUV $_{\text {lbm }}$} & WDC & 10 & $9.5 \pm 3.6$ & 0.677 & SUV $_{\text {Ibm }}$ & T1-2 & 22 & $9.37 \pm 3.3$ & 0.934 \\
\hline & MDC & 20 & $11.4 \pm 5.1$ & & & T3-4 & 14 & $11.89 \pm 5.5$ & \\
\hline & PDC & 6 & $12.8 \pm 7.4$ & & & & & & \\
\hline
\end{tabular}

Table 4. Inter-observer agreement for apparent diffusion coefficient and standardized uptake value measurements

\begin{tabular}{llll}
\hline Biomarker & $\begin{array}{l}\text { Intraclass correlation } \\
\text { coefficient }\end{array}$ & \%95 confidence interval & $\begin{array}{l}\text { Reproducibility } \\
\text { interpretation* }\end{array}$ \\
\hline ADC $_{\text {min }}$ & 0.88 & $0.73-0.94$ & Almost perfect \\
\hline ADC $_{\text {mean }}$ & 0.81 & $0.60-0.88$ & Almost perfect \\
\hline SUV $_{\text {max }}$ & 0.90 & $0.81-0.99$ & Almost perfect \\
\hline SUV & 0.95 & $0.87-0.99$ & Almost perfect \\
\hline $\begin{array}{l}\text { *Reproducibility interpretation was obtained according to Landis and Koch. } \\
\text { ADC: Apparent diffusion coefficient, ADC } \\
\text { mass-based SUV }\end{array}$ & Minimum ADC, ADC & \\
\hline
\end{tabular}

0.53-0.97 $\left.\times 10^{-3} \mathrm{~mm}^{2} / \mathrm{s}\right)$, respectively. A wide range of ADC values has been found in different studies, and this is probably due to tumor cystic or necrotic component, tumor cellularity, and presence of fibrosis (17-29). In the present study, there were no significant correlations between the histological tumor grade and the $A D C$ values, although the mean $A D C_{\text {min }}$, and $A D C_{\text {mean }}$ values tended to be lower in poorly differentiated $\left(0.64 \times 10^{-3}\right.$ $\mathrm{mm}^{2} / \mathrm{s}$, and $0.78 \times 10^{-3} \mathrm{~mm}^{2} / \mathrm{s}$, respectively) HNSSCs than in well-differentiated $\left(0.72 \times 10^{-3} \mathrm{~mm}^{2} / \mathrm{s}\right.$, and $0.89 \times 10^{-3}$ $\mathrm{mm}^{2} / \mathrm{s}$, respectively) and moderately differentiated $(0.72 \times$ $10^{-3} \mathrm{~mm}^{2} / \mathrm{s}$, and $0.84 \times 10^{-3} \mathrm{~mm}^{2} / \mathrm{s}$, respectively) HNSSCs. Increased cellularity in poorly differentiated tumors reduces the diffusion space of water protons in the extracellular matrix, with a resultant decrease in ADC. Similar results have been reported in other studies $(19,22,29,30)$. With the exception of one study that found a significant positive correlation (31), most studies found no significant correlations between the $\mathrm{T}$ stage and the ADC values $(19,22,29,32)$. Present study reports lower $A D C_{\text {min }}$, and $\mathrm{ADC}_{\text {mean }}$ values in T3-4 tumors $\left(0.67 \times 10^{-3} \mathrm{~mm}^{2} / \mathrm{s}\right.$, and $0.80 \times 10^{-3} \mathrm{~mm} 2 / \mathrm{s}$, respectively) than in T1-2 tumors $(0.69 \times$ $10^{-3} \mathrm{~mm}^{2} / \mathrm{s}$, and $0.82 \times 10^{-3} \mathrm{~mm}^{2} / \mathrm{s}$, respectively). Previous studies have indicated no significant correlations between the ADC values and tumor size or MTV $(19,30)$, and our findings are consistent.

\section{SUVs for HNSSCs}

$\mathrm{PET} / \mathrm{CT}$ is highly successful in oncological clinical practice and widely applied in the diagnosis of HNSSCs and treatment 
response evaluation. Hypercellular tumor cells show increased intracellular accumulation of the glucose analog FDG, which is expressed by an increased SUV. SUV is a convenient simple way of quantifying glucose uptake. FDG uptake is positively related to tumor cellularity and the growth rate $(30,32,33)$. Similar to the results reported in previous studies $(19,24,34$ $36)$, in the present study, the mean $S U V_{\max }$ and $S U V_{\mathrm{lbm}}$ for the HNSSCs were 14.65 \pm 5.5 (range, 7.60-29.10) and $10.96 \pm 5.1$ (range, 5.00-22.50), respectively. A wide range of SUV has been found in different studies and this is probably due to tumor cellularity, cellular turnover, tumor volume, and presence of tumor necrotic component $(35,36)$. An increase in tumor dedifferentiation can activate glucose metabolism, with a resultant increase in FDG uptake. In the present study, there were no significant differences in the SUVs among well, moderately, and poorly differentiated carcinomas, although the mean SUV $V_{\text {max }}$, and SUV $V_{\text {lbm }}$ tended to be higher in poorly differentiated (15.5, and 12.8, respectively) HNSSCs than in well-differentiated (13.3, and 9.5, respectively) and moderately differentiated (15.3, and 11.4, respectively) HNSSCs. A similar trend has been reported in other studies $(7,8,30,34,37,38)$. One study found a significant positive correlation between SUVs and T stage (19). We found no significant correlations between the SUVs and T stage; however, mean SUV $V_{\max }$, and SUV $\mathrm{Ibm}_{\mathrm{bm}}$ were higher in T3-4 tumors (16.15, and 11.89, respectively) than in T1-2 tumors (12.10, and 9.37, respectively). With the exception of one study (39), previous studies have reported positive correlations between SUVs and MTV $(32,33,36,38)$. However, in the present study, the correlations between SUVs and MTV did not reach statistical significance.

\section{Correlations between ADC values and SUVs in HNSSCs}

It is important to assess whether the ADC values and the SUVs are statistically independent or correlated, as recent data suggest that both types of biomarkers may be associated with cell proliferation and may predict the response to RT and chemotherapy (19). Recent researches suggest that these two biomarkers may be correlated with tumor cellularity, cell proliferation, and tumor necrosis (19). The present study did not identify significant correlations between the SUVs and the ADC (800) values, indicating that these biomarkers are independent in HNSSCs. With the exception of one study that found a significant inverse correlation of these two quantitative parameters (19), previous studies reported results similar to our findings $(18,20,24,34-36,40)$.

\section{Inter-observer agreement}

Previous analyses reported almost excellent interreader agreement for SUV $_{\max }$ values for lung cancer, sarcomas, breast cancer and HNSCCs. These studies have shown that the SUV $_{\text {max }}$ is reproducible and observer-independent value. The present study identified almost perfect inter-observer agreement for the ADC values and the SUVs. Compared to the previous data, we found slightly inferior interreader reliability [ICC = 0.81-0.88 versus 0.96 (reported)] for ADC values (24) and almost equal interreader reliability [ICC $=0.90-0.95$ versus 0.97 (reported)] for SUVs (24).

Our study has several limitations. This study was retrospective and involved a small number of patients. From this small sample size, it is difficult to draw firm conclusions. Further validation is required with a large number of cases. Different acquisition parameters including matrix size and slice thickness affect both the quality and quantitative values of MRI and PET images in the current study.

\section{Conclusion}

In conclusion, our results suggest that pretreatment ADC values and SUVs for HNSSCs are independent and reproducible biomarkers, with almost perfect inter-observer agreement. The ADC values tended to be lower and the SUVs tended to be higher in T3-4 stage and poorly differentiated HNSSCs; however, the findings were not significant. Further large-scale, multi-institutional studies should be performed to provide standardized pretreatment ADC and SUV cut-offs for characterization, prediction, treatment response assessment, and the detection of post-treatment changes and recurrent head and neck tumors.

\section{Ethics}

Ethics Committee Approval: Approval for the study was granted by the Ethics Committee of Ege University Faculty of Medicine (approval date: February 12, 2013, approval number: 13-1/50).

Informed Consent: Retrospective study.

Peer-review: Externally peer-reviewed.

\section{Authorship Contributions}

Surgical and Medical Practices: E.C., S.B., O.A., Concept: E.C., S.B., Design: E.C., S.B., Data Collection or Processing: E.C., S.B., O.A., Analysis or Interpretation: E.C., S.B., O.A., R.S., M.E., Literature Search: E.C., S.B., O.A., R.S., M.E., Writing: E.C., S.B., O.A.

Conflict of Interest: No conflict of interest was declared by the authors.

Financial Disclosure: The authors declared that this study received no financial support.

\section{References}

1. Argiris A, Karamouzis MV, Raben D, Ferris D. Head and neck cancer. Lancet 2008;371:1695-1709.

2. Seitz $O$, Chambron-Pinho $N$, Middendorp $M$, et al. 18F-Fluorodeoxyglucose-PET/CT to evaluate tumor, 
nodal disease, and gross tumor volume of oropharyngeal and oral cavity cancer: comparison with MR imaging and validation with surgical specimen. Neuroradiology. 2009;51:677-686.

3. Thoeny HC, De Keyzer F, King AD. Diffusion-weighted MR imaging in the head and neck. Radiology. 2012;263:19-32.

4. Al-lbraheem A, Buck A, Krause BJ, Scheidhauer K, Schwaiger M. Clinical applications of FDG PET and PET/ CT in head and neck cancer. J Oncol. 2009;2009:208725.

5. Liu S, Zheng $\mathrm{H}$, Zhang $\mathrm{Y}$, et al. Whole-volume apparent diffusion coefficient-based entropy parameters for assessment of gastric cancer aggressiveness. J Magn Reson Imaging. 2018;47:168-175.

6. Cui L, Yin JB, Hu CH, Gong SC, Xu JF, Yang JS. Interand intraobserver agreement of ADC measurements of lung cancer in free breathing, breath-hold and respiratory triggered diffusion-weighted MRI. Clin Imaging. 2016;40:892-896.

7. Liu L, Liu Y, Xu L, et al. Application of texture analysis based on apparent diffusion coefficient maps in discriminating different stages of rectal cancer. J Magn Reson Imaging. 2017;45:1798-1808.

8. Schob S, Meyer HJ, Pazaitis N, et al. ADC Histogram Analysis of Cervical Cancer Aids Detecting Lymphatic Metastases-a Preliminary Study. Mol Imaging Biol. 2017;19:953-962.

9. KruskalW, Wallis A. Use of ranks in one-criterion variance Analysis. J Am Stat Assoc. 1952;47:583-621.

10. Donner A, Koval JJ. The estimation of intraclass correlation in the analysis of family data. Biometrics. 1980;36:19-25.

11. Landis JR, Koch GG. The measurement of observer agreement for categorical data. Biometrics. 1977;33:159-174.

12. Sinha S, Lucas-Quesada FA, Sinha U, DeBruhl N, Bassett LW. In vivo diffusion-weighted MRI of the breast: potential for lesion characterization. J Magn Reson Imaging. 2002;15:693-704.

13. Huisman TA, Loenneker T, Barta G, et al. Quantitative diffusion tensor MR imaging of the brain: field strength related variance of apparent diffusion coefficient (ADC) and fractional anisotropy (FA) scalars. Eur Radiol. 2006;16:1651-1658.

14. Kim S, Loevner L, Quon H, et al. Diffusion-weighted magnetic resonance imaging for predicting and detecting early response to chemoradiation therapy of squamous cell carcinomas of the head and neck. Clin Cancer Res. 2009;15:986-994.

15. Fushimi $\mathrm{Y}$, Miki $\mathrm{Y}$, Okada $\mathrm{T}$, et al. Fractional anisotropy and mean diffusivity: comparison between 3.0-T and 1.5$\mathrm{T}$ diffusion tensor imaging with parallel imaging using histogram and region of interest analysis. NMR Biomed. 2007;20:743-748.

16. Matsuoka A, Minato M, Harada M, et al. Comparison of 3.0and 1.5-tesla diffusion-weighted imaging in the visibility of breast cancer. Radiat Med 2008;26:15-20.
17. Preda L, Conte G, Bonello L, et al. Combining standardized uptake value of FDG-PET and apparent diffusion coefficient of DW-MRI improves risk stratification in head and neck squamous cell carcinoma. Eur Radiol. 2016;26:4432-4441.

18. Choi SH, Paeng JC, Sohn CH, et al. Correlation of 18F-FDG uptake with apparent diffusion coefficient ratio measured on standard and high $b$ value diffusion MRI in head and neck cancer. J Nucl Med. 2011;52:1056-1062.

19. Nakajo M, Nakajo M, KajiyaY, et al. FDG PET/CT and diffusion-weighted imaging of head and neck squamous cell carcinoma: comparison of prognostic significance between primary tumor standardized uptake value and apparent diffusion coefficient. Clin Nucl Med. 2012;37:475-480.

20. Vandecaveye V, Dirix P, De Keyzer F, et al. Predictive value of diffusion-weighted magnetic resonance imaging during chemoradiotherapy for head and neck squamous cell carcinoma. Eur Radiol. 2010;20:1703-1714.

21. Meyer HJ, Leifels L, Schob S, Garnov N, Surov A. Histogram analysis parameters identify multiple associations between DWI and DCE MRI in head and neck squamous cell carcinoma. Magn Reson Imaging. 2017;45:72-77.

22. Ichikawa Y, Sumi M, Sasaki M, Sumi T, Nakamura T. Efficacy of diffusion-weighted imaging for the differentiation between lymphomas and carcinomas of the nasopharynx and oropharynx: correlations of apparent diffusion coefficients and histologic features. AJNR Am J Neuroradiol. 2012;33:761-766.

23. Han M, Kim SY, Lee SJ, Choi JW. The Correlations Between MRI Perfusion, Diffusion Parameters, and 18F-FDG PET Metabolic Parameters in Primary Head-and-Neck Cancer: A Cross-Sectional Analysis in Single Institute. Medicine (Baltimore). 2015;94:21-41.

24. Varoquaux A, Rager O, Lovblad K, et al. Functional imaging of head and neck squamous cell carcinoma with diffusionweighted MRI and FDG PET/CT: quantitative analysis of ADC and SUV. Eur J Nucl Med Mol Imaging. 2013;40:842852.

25. Chawla S, Kim S, Dougherty L, et al. Pretreatment DiffusionWeighted and Dynamic Contrast-Enhanced MRI for Prediction of Local Treatment Response in Squamous Cell Carcinomas of the Head and Neck. AJR Am J Roentgenol. 2013;200:35-43.

26. Meyer H, Purz S, Sabri O, Surov A. Relationships between histogram analysis of ADC values and complex 18F-FDGPET parameters in head and neck squamous cell carcinoma. PLoS One. 2018;13:e0202897.

27. King AD, Chow KK, Yu KH, et al. Head and neck squamous cell carcinoma: Diagnostic Performance of Diffusionweighted MR Imaging for the Prediction of Treatment Response. Radiology. 2013;266:531-538.

28. Sakamoto J, Sasaki Y, Otonari-Yamamoto M, Sano T. Comparison of various methods for quantification of apparent diffusion coefficient of head and neck lesions with HASTE diffusion-weighted MR imaging. Oral Surg Oral Pathol Oral Radiol. 2012;114:266-276. 
29. Kato H, Kanematsu M, Tanaka O, et al. Head and neck squamous cell carcinoma: usefulness of diffusion-weighted MR imaging in the prediction of a neoadjuvant therapeutic effect. Eur Radiol. 2009;19:103-109.

30. Surov A, Stumpp P, Meyer HJ, et al. Simultaneous (18) F-FDG-PET/MRI: Associations between diffusion, glucose metabolism and histopathological parameters in patients with head and neck squamous cell carcinoma. Oral Oncol. 2016;58:14-20.

31. Hatakenaka M, Nakamura K, Yabuuchi $H$, et al. Pretreatment apparent diffusion coefficient of the primary lesion correlates with local failure in head-and-neck cancer treated with chemoradiotherapy or radiotherapy. Int J Radiat Oncol Biol Phys. 2011;81:339-345.

32. Leifels L, Purz S, Stumpp P, et al. Associations between 18F-FDG-PET, DWI, and DCE parameters in patients with head and neck squamous cell carcinoma depend on tumor grading. Contrast Media Mol Imaging. 2017;2017:536925.

33. Li Q, Zhang J, Cheng W, et al. Prognostic value of maximum standard uptake value, metabolic tumor volume, and total lesion glycolysis of positron emission tomography/ computed tomography in patients with nasopharyngeal carcinoma: A systematic review and meta-analysis. Medicine (Baltimore). 2017;96:80-84.

34. Fruehwald-Pallamar J, Czerny C, Mayerhoefer ME, et al. Functional imaging in head and neck squamous cell carcinoma: correlation of PET/CT and diffusionweighted imaging at 3 Tesla. Eur J Nucl Med Mol Imaging. 2011;38:1009-1019.
35. Haerle SK, Huber GF, Hany TF, Ahmad N, Schmid DT. Is there a correlation between 18F-FDG-PET standardized uptake value, $\mathrm{T}$ classification, histological grading and the anatomic subsites in newly diagnosed squamous cell carcinoma of the head and neck? EurArch Otorhinolaryngol. 2010;267:1635-1640.

36. Imsande HM, Davison JM, Truong MT, et al. Use of 18F-FDG PET/CT as a predictive biomarker of outcome in patients with head-and-neck non-squamous cell carcinoma. AJR Am J Roentgenol. 2011;197:976-980.

37. Surov A, Stumpp P, Meyer HJ, et al. Simultaneous (18) F-FDG-PET/MRI: Associations between diffusion, glucose metabolism and histopathological parameters in patients with head and neck squamous cell carcinoma. Oral Oncol. 2016;58:14-20.

38. Surov A, Meyer HJ, Höhn AK, Winter K, Sabri O, Purz S. Associations Between [18F]FDG-PET and Complex Histopathological Parameters Including Tumor Cell Count and Expression of KI 67, EGFR, VEGF, HIF-1a, and p53 in Head and Neck Squamous Cell Carcinoma. Mol Imaging Biol. 2019;21:368-374.

39. Döbert N, Kovacs AF, Menzel C, et al. The prognostic value of FDG PET in head and neck cancer. Correlation with histopathology. Q J Nucl Med Mol Imaging. 2005;49:253257.

40. Covello M, Cavaliere C, Aiello M, et al. Simultaneous $\mathrm{PET} / \mathrm{MR}$ head-neck cancer imaging: Preliminary clinical experience and multiparametric evaluation. Eur J Radiol. 2015;84:1269-1276. 